\title{
Geopolitics of Climatic Change and Depleting Environmental Resources and Its Impact
}

\author{
Dr. Nawaz Ahmed
}

\begin{abstract}
It was only fifty years before that our scientists and experts on climate and environment started the keen observation that something wrong is happening to our environment. The result was that the far-sighted people in the world began emphasizing that human community should take an approach of sustainable living, growth and development.

A large number of national and international conferences on sustainable development have been held during the last 40 years to chalk out workable strategies to counter act the impending catastrophes, but till date all these conclaves have been proved to be futile exercises. Such as: Stockholm Conference (1972), Helsinki (1989), London (1992), Rio-Summit (1992), Kyoto- Summit (1997), World Summit on Sustainable Development Johannesburg (2002), Stockholm and Montreal Summit in 2004 and 2005 and the later Berlin Conference 2007. Bali Conference (2007) agreed on all the agenda.

The above strategies, i.e., to make the people aware with the dire consequences of the natural hazards of climate and environmental change, the corporate political and business circles has neither reduced nor stopped the emission of Green House Gases (GHGS). By keeping the people uninformed and unorganized in all these high get - together, the U.S. has played the chief Criminal role to disrupt and undermine all these high get- together by refusing to accept their respective basic decisions and confusing the people all over the world and harming the human cause. Therefore, there is an urgent need to reject the objectives of the corporate thinkers, experts, politicians and economists and all the different brands of humanitarian and environmental forces come forward and unite themselves on the basis of common agenda and organize the people on a single platform for saving our planet earth, our environment and combating global warming. Unless and until the people and resources are not considered the most precious thing in the society the corporate capitalism falsifies that only capital is the most precious things in society. Secondly it is necessary to have in mind and in practice both that the fundamental human task is environmental sustainability at all times and at all places. Lastly, our next principle should be the all round constitutional empowerment of the people such as (i) Economic empowerment and social security and fundamental right to have the clean air, pure-drinking water, protective and nutritious food, housing, clothing and free health facilities and education etc. fair equality based on 1:5 income difference in order to bring economic harmony among the extremely divided categories of a handful of rich and the vast majority of poor people. If it is not tackled poverty and pollution may be considered coterminous as one of the factors, (ii) Political empowerment which should be characterized as involvement of dedicated social worker, right of vote and candidature for election be allowed, peoples sponsored candidate should be elected for election to raise the issue of environment, (iii) Cultural empowerment based on a life style with environmental values.
\end{abstract}

\section{Analysis Of Environmental Degradation}

An analysis of environmental degradation in general and each of its components in particular is very necessary in an integrated manner. Eco-bio challenge facing the human society today is fatal and if not tackled within a few decade or so, it would, according to expert opinion, become uncontrollable, pushing the human species (along with other bio-phenomena) for their final doom, thus wiping off the existence of all varieties of living matter on this earth. The environmental degradation is mainly caused by variety of pollutions which arises from the existing chemical based and mainly thermal power driven capitalist technology (related to manufacturing, agriculture, information industry etc). Our environment is comprised of air water land and biodiversity (including forests)

1. Air pollution today constitutes the chief threat to the bio-life on our planet. It has become the major killer of the people. The emissions of carbon and other greenhouse gases have been trebled during the past three decades, creating global warming and climate change as a serious threat to all bio-life. U.S alone creates about $30 \%$ green - house gas emissions which is the chief polluter of the world.

2. Water pollution as a major component of environment is scarcely available for all the sectors such as hydroelectricity, irrigation, safe drinking water and industrial- urban water. Over $50 \%$ of world population now faces chronic shortage of fresh water for daily needs. Over $60 \%$ of the world's wetlands have been lost and $25 \%$ of the ten-thousand fresh water species is extinct. The contaminated water kills millions of people every year and we have the largest number of water - borne diseases. 
3. Half of the world's forests have been destroyed and utilized. The existing rate of loss is about 90,000 sq. km every year. These may extinct in the next 25 years. Now two- third of the world's farmlands suffer from soil degradation. Over half of the grass lands are overgrazed. India is facing a critical stag and challenge.

4. About more than thousand species of wild life have become extinct and about 12,000 more are in threatened list. About 755 of the world's marine captures is over fished or fully utilized. In North America, 10 fish species went extinct in 1990 of the 9946 known bird species, $70 \%$ has declined in number. Population growth with better skill than the past utilizing the resources in much faster manner. Since 1930 about 4 billion population is added in 2 billion populations. In ten years world will have to feed a house another billion.

5. The year 2005 has been a sort record for natural disasters around the world. From Tsunami which wrecked the coasts of Sumatra, India and Sri Lanka, to the Pacific Ocean, typhoons in Japan, Taiwan, China, and SE Asia, to the super-hurricanes in the Gulf of Mexico and United States, to the deadly mudslides and flooding of Mumbai, Guatemala, Elsalvador and Mexico, Cyclones in Andhra Pradesh and Tamil Nadu, unraesed stresses along the Himalayan fault line and in the Muzaffarabad earthquake in Kashmir all are super disasters killing hundred of thousands and destroying everything in their wake. That is nature's fury. There are other disasters in making such a wide - spread bird flu killing millions of bird which wrecked the global economy. For all theses climate changes is held responsible.

\section{AWARENESS ANd SCIENTIFIC OPINION IN THE WORLD}

The scientific community has since been sounding the worsening state of our natural environment. A large number of reports have already been released by various scientists. A reference of only few is mentioned here:

1) In an article published in 2004 January in a scientific magazine "NATURE" relates that "Climate Change over the next fifty years is expected to drive a quarter of land animals and plants into extinction". The other scientific experts also admit that the environmental situation is highly alarming.

2) The March 2004 UN report says that the "Smokeless Industry" of information technology is a major global pollutant. According to it a $24 \mathrm{~kg}$ computer along with 27 centimetre cathode ray tube monitor required at least $230 \mathrm{~kg}$ of fossil fuel, $22 \mathrm{~kg}$ of chemical and $1500 \mathrm{~kg}$ of water - a total of 1.8 tones.

3) The March 2004 report of the Natural Environment Research Council Centre for ecology and hydrology in Dorchester, U.K. says, "A sixth massive extinction event in the history of life is upon us yet again". Such mass extinctions of living species of flora and fauna have periodically occurred during the five gigantic prehistoric extinctions. The Dorchester, U.K. Centre says that previous five extinctions occurred due to the interplay of natural causes, while the Sixth one seems to be due to human activity.

4) The 2003 Rome Conference of the World noted scientists has cautioned that if the worsening progress of environmental degradation is not reversed within a short time, the earth will become totally unsuitable for bio-living in the near future.

5) A study in 2002 made by UN world life fund has warned that if the human community (especially the rich nations) does not change its extravagant and wasteful life -style, our earth will become unsuitable by 2050 .

6) The 2000 UN Johannesburg World Summit on sustainable development was held to consider the fatal problem of environment and human resource degradation. The 2000 statement issues by 6000 internationally prominent scientists has emphasized that if the human community did not stop the production of green - house gases in a short span of time, the global warming would make the earth uninhabitable for bio-life by the end of the $21^{\text {st }}$ century.

The public perception is also running on similar lines. The people have a feeling that the constantly increasing volume of green- house gases, depleting global water resources, large scale deforestation, degradation of more than $60 \%$ of arable land, dying out of many bio-species and unsustainable use of other natural products is creating a very serious threat for them.

The whole responsibility to environmental degradation goes to corporate institutions in the world such as UN, WB, IMF, Nation States and prominent social scientists, thinkers and planners. The ongoing Eco-bio crisis is the outcome of human activity. But none of them have ever define the concept of public activity neither in World Summits of 1972, Rio-UN Summit and 2002 Johannesburg, they have made only a passing reference to the unsustainable human ways and life-style. According to the general theory that every human is polluting but everyone knows this fact that the responsibility of producing pollution rests with those who own pollutant producing factories and farms and not the workers engaged in those enterprises. Now the question arises as to who should organize the repairing work to climate change damage. Since corporate sector is the creator of the climate crisis and since all major powers have so far failed to make a proper response to the environmental changes occurring in the past, it will be more appropriate that the present climate repairing task should be handed over to the U.N general Assembly instead of entrusting it over to the Security Council or G8 group, both of which are dominated by vested interests of big corporate powers. In the General Assembly where the 
decisions are taken on the majority basis, there is little likelihood of the superpower or rich nation's dominations. But it is also a very sad experience that U.S has refused to endorse the 1997 Kyoto Protocol as approved by the whole human world regarding the environmental issues. It produces the logic that the American economy will be harmed if it stops or reduce the production level and minimize the GHGS.

Since the beginning of the $21^{\text {st }}$ century U.S is on a campaign trail to seize control of all the important environmental resources in various countries of the world by all means using firstly the business tricks and finally the military force.

India is also going to be affected at large scale in future by many catastrophes if greater awareness is not taken by the people and the govt. of the country on many issues involved in the complex problem.

\section{Impact Of Overexploitation And Degradation Of Natural Resources.}

The impact of overexploitation and degradation of the natural resources on which human beings was earning their livelihood since centuries and was living in a highly decent manner, may not live after the over exploitation and degradation of resources. The impact is seen through the sustainability of resources. If sustainability is lost survival of mankind is not possible for a longer time. The major impacts of overexploitation of natural resources are as follows:-

1. Degradation of soil, water and vegetation resources;

2. Large volumes of domestic waste - pollution problems;

3. Social environment problems - crime

4. Stress on health and social welfare facilities

5. Impact on infrastructure

6. Over utilization of natural resources

7. Potential spread of communicable diseases

8. Land transformation

9. Loss of biodiversity and ecosystems

\section{STRATEGIES FOR CONTROLLING THE PROBLEM}

1. Efficiency of Energy and Conservation

2. Fuel Efficient Vehicles

3. Alternative Energy Source- nuclear, renewable and burning waste methane.

4. Carbon capture and Storage

5. Societal controls and people participation

6. Governmental and intergovernmental Action- Kyoto protocol

7. Non govt. approaches - legal action and personal choices

8. Population control

\section{References}

[1]. Ahmad, Y. J, Serafy, S. E and Lutz, E. (eds) 1989, Environmental Accounting for Sustainable Development, The World Bank, Washington, D.C

[2]. Carley, M. 1994, Policy Management Systems for Sustainable Agriculture and Rural Development, International Institute for Environment and Development and Food and FAO, Rome.

[3]. Crosson, P. and Anderson, J. R. 1993, Concerns for Sustainability: Integration of Natural Resource and Environmental Issues for the Research Agendas of NARS, Research Report 4, ISNAR, The Hague.

[4]. Crosson, P. and Anderson, J. R.1995a, Achieving a Sustainable Agricultural System in Sub-Saharan Africa, Building Blocks for Africa 2025, Paper No.2,AFTES, The World Bank, Washington, D.C.

[5]. Elliot, Jennifer A 1994. An Introduction to Sustainable Development, Routledge, London. Govt. of India. 1998. 'Water Statistics of India'. Central Water Commission, New Delhi.

[6]. FAO. 1989, 'Sustainable development and natural resources management', Twenty-Fifth Conference, Paper C 89/2 - Sup. 2, Food and Agriculture Organization, Rome.

[7]. Munasinghe, M. 1993, Environmental Economics and Sustainable Development, World Bank Environment Paper No. 3, The World Bank, Washington, D.C.

[8]. Pezzey, J. 1992, Sustainable Development Concepts: An Economic Analysis, World Bank Environment Paper No. 2, The World Bank, Washington, D.C. 